\title{
Body Language and Gestures as a Lingua Franca among Multilingual Interlocutors: Multimodal Transcription Study
}

\author{
Cynthia L. Soegiono ${ }^{1}$, Laily M.S. Harti ${ }^{1, *}$, Sueb Sueb ${ }^{2}$ \\ ${ }^{1,2}$ Universitas Negeri Surabaya, Indonesia \\ *Corresponding Author. Email lailyharti@unesa.ac.id
}

\begin{abstract}
Lingua franca is known as the language bridge between two different people who have different native languages. The theory stated that humans communicate by using vocal organs and the whole part of the body. This study was conducted to seek out whether non-verbal language could be considered lingua franca. This study used multimodal transcription analysis with Jefferson and Modada transcript notation and has decided on several data clips from YouTube. The study examines the gestures and other non-verbal languages to seek out whether multilingual interlocutors could receive the implied message delivered by body language. The results show that the hearer was trying to understand the speaker's gesture. The speaker does not speak English fluently, so he was struggling to find perfect diction. At the end of the clip, the speaker finally succeeds in portraying his thoughts through some gestures. In addition, the interlocutors were taking place in the action of delivering and receiving implied meaning through gestures and body language. Even though there was already a lingua franca (e.g., English), body language adds meaning through the message. Furthermore, this study was conducted in order to give a different insight into the term lingua franca.
\end{abstract}

Keywords: Body language, Lingua franca, Multimodal transcription.

\section{INTRODUCTION}

Human beings who do not fully acquire their second language often use their gestures and body language to transfer and portray their thoughts to their interlocutors. Hence, language is not the only means of communication, as our body could portray our thoughts while communicating with others. We speak with our vocal organ, but we converse with our entire bodies [1]. When people are talking, they will use their vocal organs to do so most of the time. But what about their gestures and body language? Language is not all about the vocal organ. Language could also be conducted with signs such as Sign Language used by deaf people to communicate [2]. There are so many sign languages around the world (i.e., American Sign Language, Asian Sign Language, Chinese Sign Language, etc.). Still, this study focuses more on interpreting our thoughts, known as body language [3].

Lingua Franca is nothing strange for bilingual or multilingual people. It is also very familiar for the Interpreter jobs for helping their clients to make some deals or any kind of formal situation that includes two different native speakers with a different native language in order to gain a successful conversation [4]. The most common language as a Lingua Franca is English [4] since it is an international language, where everybody can learn it institutionally.

People around the world have already learned a language in order to deliver their thoughts and minds. However, some people are having trouble while doing so. To interpret their thoughts, people sometimes use the term 'Body Language' [5]. [5] conducted their study in order to understand the struggle of how two different native speakers had a conversation without the help of good English skills. The subjects were a native Japanese student and a native Indonesian student who had a conversation in their canteen. They used gestures such as shaking and pointing their hands while delivering their speech to maximize their speaking. The results were surprisingly good since the gestures of moving hands and pointing are essential for this kind of multilingual interlocutors. The study proves that even though they did not master their English speaking skills, body language helps them successfully initiate and bait 
the interlocutors to continue their conversation. Another study has been conducted by [6] as they found out that a movement from a traditional Indonesian dance could also deliver a message through an advertisement in Garuda Airlines. This study examines the gestures and other non-verbal languages to seek out whether multilingual interlocutors could receive the implied message delivered by body language. In particular, to have more profound knowledge, this study has given birth to several questions: What kind of body language does the person use? Or what factor affects a person's use of body language to portray their thoughts? Or even how can the hearer receive the meaning from the speaker's body language?

Lingua franca is a bridge language between two different native speakers [4]; [7]. Body language might implied a hidden meaning during conversations. Body language during a conversation might help two different native speakers communicate to each other because of the implied meaning created by the body language. Suppose there are two different people who use English as their language to communicate. Yet, one of them also uses gestures such as moving their hands or raising their eyebrows to enhance and make the conversation easier to understand. This kind of gesture has a hidden meaning, as mentioned by Navarro and his colleagues in his book "The Dictionary of Body Language" [3]. This explained that the body language and lingua franca might be synced in a conversation between two different people who speak different native languages.

\subsection{Body Language as Lingua Franca}

This world consists of people varied in culture, race, law, and of course, language. Language around the world has so many varieties, and there are many native speakers in each language. This diversity has rised a problem, especially when the two different native speakers met and wanted to talk. Lingua Franca is the only way to help them communicate with each other. Based on [4], Lingua Franca is the bridge language to help the two or more different native speakers to achieve a successful conversation. Imagine how difficult it would be if a person came from China and met an Italian person, and they wanted to negotiate for their company. Still, they did not understand each native language. In this kind of situation, Lingua Franca came to rescue them.

Lingua Franca is not only used for international purposes. There are also a lot of examples that lingua franca could be used in the national region of a country [4] [8]. As one of the examples, in Indonesia, there are many different regional languages, such as Javanese, Sundanese, Balinese, Madurese, etc. Suppose that there are representatives from each region and are all native to each language. If the meeting used their native region language, the conversation might fail since they do not understand each region's language but their native language [4]. In Indonesia, the national language is Indonesian (Bahasa Indonesia). If they use this national language, Indonesian is already categorized as a lingua franca since this national language became the bridge between these regional native speakers, and the conversation is thriving.

In terms of Body Language, there are a lot of things worth discussing, such as why we roll our eyes if we do not like something [3]. A gesture such as women playing with their hair while talking to somebody or someone raising their eyebrows could interpret and implied an indirect meaning that words could not say, such as a girl playing with her hair while waiting for an interview. According to [3], this kind of interaction is known as "pacifying behavior." It is the same as a baby sucking at its thumb to soothe him emotionally. This behavior usually indicates a good mood or even tension. This theory proves that some action might have something a word cannot do because this kind of behavior is under our subconscious level.

Another example is when we raise our eyebrows, making an asymmetric shape, noting that it implies disagreement or dislike. These body language helped us express ourselves when interacting with somebody else without actually saying our thoughts. It is more like the action version of an implicature popularized by [9]; [10] while an Implicature is an implied meaning from words, the body language is an implied meaning without even saying the words.

\subsection{Body Language and its Part}

Body language is a very general term. From the top of the entire body, the head is one of the essential parts since all of our minds, thoughts, and actions come from our heads [3]. Head, including eyes, eyebrows, hair, and even head movement, might contain a specific implied meaning, and we might want to pay attention to those kinds of parts while speaking with our interlocutor. While speaking with a person, we might want to pay attention to those little parts of a person's body. Hence, we could seek a hidden meaning through their gestures [2]. For example, when a person likes to raise their eyebrows and stroking their hair constantly, this implies a hidden meaning where the person is stressing out of something [3]. Since the hidden meaning is already shown, the involved interlocutors could understand better.

Not only is the head an essential part of a body, but the entire body parts are also essentials. While communicating, interlocutors must observe other body parts that make some gestures, such as torso, arms, legs, as their movement could bring another implied meaning [3]. Suppose there are some group of people was talking to each other. One of the members of the group slowly 
raised his eyebrows. According to [3], the meaning of a person raising his eyebrows is either surprised or concerning the context of the conversation. While another part of the human body also contains a lot of mystery, such as why we did those kinds of gestures, why is she playing with her hair? Why is he scratching his head while rubbing his stomach? Such natural behavior still becomes a hot debate since gestures might not have similar meanings [3].

\subsection{Understanding Gestures and Signs in Lingua Franca Context}

Lingua franca can be used in various ways [8]. The function of the lingua franca itself is to become the bridge between two different native speakers. Even though they have difficulties while delivering their speech [5], lingua franca is still in the context and as long as the interlocutors understand what is portrayed by the speaker because a successful conversation is not by how the interlocutors mastered the language but by simply understanding each other's minds. In this context, lingua franca is not only limited to spoken language. It could be anything, including sign language, body language, spoken language, or any kind of code since lingua franca is described as a language used by whose mother tongues are different [8].

Since body language could be considered a lingua franca, understanding each gesture that the interlocutors made is essential. This study focuses on how a gesture could bring the message from one to another interlocutor. Navarro and his colleagues [3] have made a dictionary of body language. The meaning behind the gestures might bring a message since the body language contain a piece of non-verbal information that might be needed while having a conversation [3]. Suppose that the target person already understands the hidden meaning from gestures and body language, then the conversation is successful in a lingua franca context.

\section{METHODS}

The study has already chosen some data to be analyzed. The first data was a video in a local Korean tv show inviting a native English speaker to interact with some Korean idols to speak the English language. The second data set was a video from the TV show Asian Next Top Model Season 4 where a Korean model was yelled at by one of the judges for giving lousy body language in one of the episodes. Since the data of the study was a transcript of a conversation and additional frames of pictured, this study belongs to the qualitative method [7]; [11]. This particular method was portrayed because the data contains words and utterances rather than numbers [12]. This study also used Multimodality and some part of Conversation Analysis. The data set was a video in which the actions, including tones, hand gestures, and body language portrayed by the video. The Conversation Analysis was used to understand the transcript of the conversation, including the pauses that might have implied some meaning which might help conclude the study.

The study analysis began with collecting data and classifying whether the data includes gestures or body language. After the data has been classified, this study applied the multimodal transcription, where transcription of images, video, voice tone, gestures are parts of multimodal, as a part of the qualitative research method [7]. The transcription began with identifying each of the utterances and gestures considering the tones showed by the interlocutors, pauses and gaps, speaking rate, and particular maintained actions [13]; [14]. The particular data that have been analyzed will be translated with body language dictionary by [3] to seek the implied meaning and understanding of whether the gestures or body language made by the interlocutors were transmitted successfully.

\section{RESULTS AND DISCUSSION}

The first clip resulted in how the body language is successfully interpreted by the native speaker. The activities in lines 8 and 9 prove that the native English speaker catches a slight hint of the native Korean speaker's activity. The second clip resulted in how the body language also succeeds in interpreting the body language of SA. The gesture of SA raising her eyebrow affects G's feelings, and he is apparently mad about this behavior. The transcript that was used by this study is using Jefferson transcript notation [14] and Modada transcript notation [15]. The translation codes are written below in order to give a better understanding while observing the precise manual transcript from the data.

(.) $=$ Short pause interval under 0 second

$[\ldots]=$ Overlapping speech

$>\ldots<=$ Indicates increasing speaking rate (speeding up)

$\circ \ldots \circ=$ Indicates whisper

$($ time $)=$ Timelapse in absolute seconds

$\Delta=$ Indicates action

${ }^{\uparrow}=$ Pitch up

$\downarrow$ Pitch down

$(\mathrm{Lx})=$ actions maintained until a certain line

The First Clip

Transcript Korean Idol Vs. English Funny Moments https://youtu.be/cyfLh9ixMyM

INT = Interviewer

RES $=$ Respondent

AU1 = Unknown Audience 1

Interview: Male Native English Speaker 
Respondent: Male Native Korean Speaker Audience: Male Native Korean Speaker

1 INT : What did you do $>$ Yesterday $<$ ? Tell me what you did..

3 RES $\quad \stackrel{(3.0)}{{ }^{\uparrow} \mathbf{A H}}$

$4 \quad(3.1)$
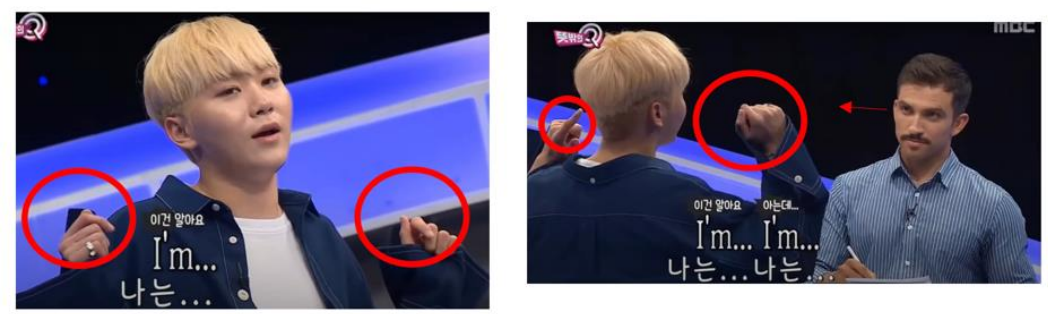

$5 \quad$ RES : ${ }^{\downarrow} \mathbf{I}$ 'm.. .hhh ${ }^{\downarrow} \mathbf{I}$ 'm.

$\Delta$ start raising both $\mathrm{H}$ while avoiding GZ with INT

INT $: \triangle$ INT GZ at RES (L.19)

$6 \quad(1.0)$

RES : ${ }^{\downarrow}$ Uh.
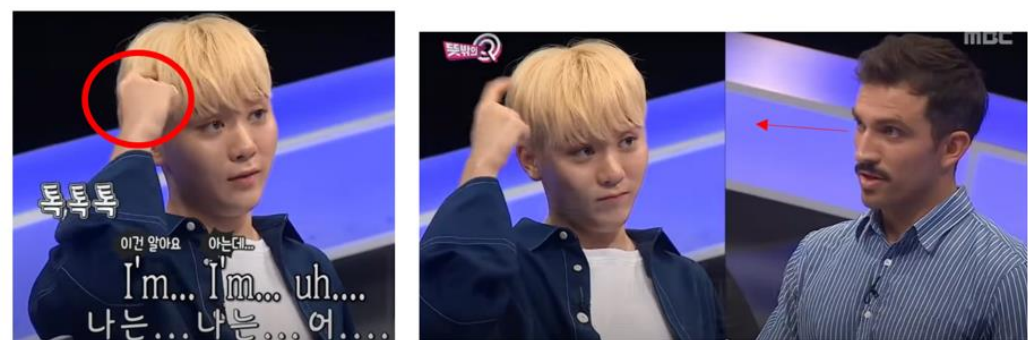

8

(3.0)

RES : $\triangle$ RES pointing and knocking his HD

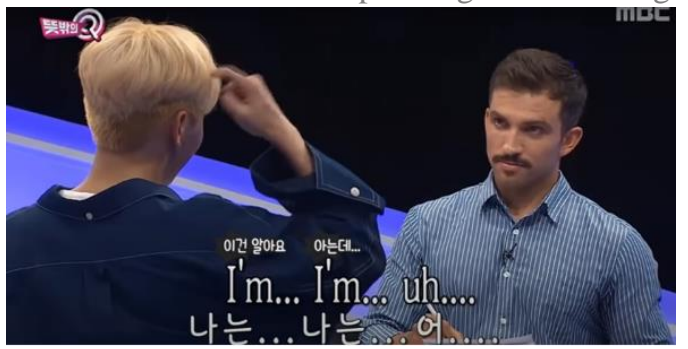

$9 \quad$ INT $\quad:>$ Your $<$ Head?

$10 \quad(1.0)$

11 RES : ${ }^{\downarrow}$ My.. ${ }^{\dagger}$ Hair

12 INT : > Uh $\mathbf{h m}<$ ?
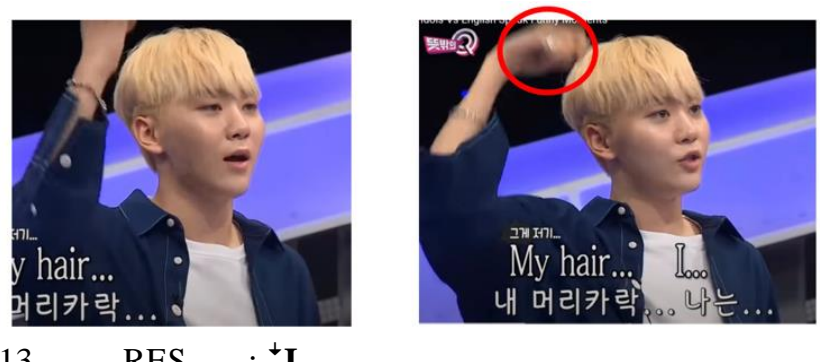

13

$\triangle$ RES starts to mimic shower gesture

$\triangle$ RES fisting $\mathrm{P}$ and waving back and forth

$14 \quad(1.0)$

15 RES : > Shampoo!< 


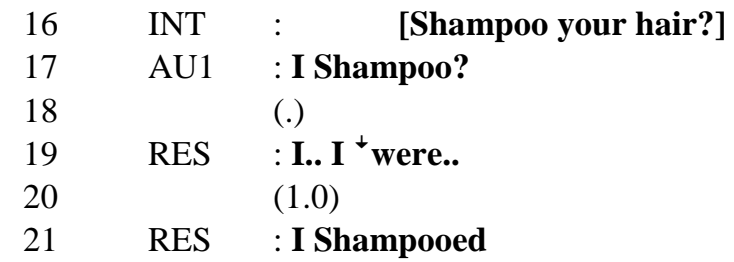

\section{The Second Clip}

Transcript ANTM Season 4

https://www.youtube.com/watch?v=WznzvqtPmd8\&t=1s

SA = Sang In

$\mathbf{G}=$ Glenn

FJ = Female Judge

MJ1 = Male Judge 1

MJ2 = Male Judge 2

1 FM : It was all about portraying confidence in motion, am I correct, Glenn?

$2 \quad(1.0)$

3 G: I'm the client. I'm the one who gave the brief, but she is the first one who ${ }^{\uparrow}$ rolles her ${ }^{\uparrow}$ eyes to ${ }^{\top}$ me!

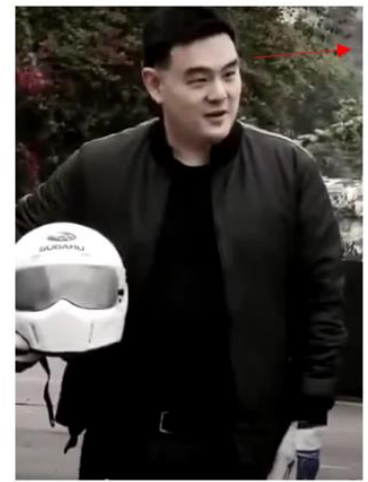

4 Flashback

5 G: You're gonna get in the car and strike a pose

$\Delta$ G smiles while giving brief
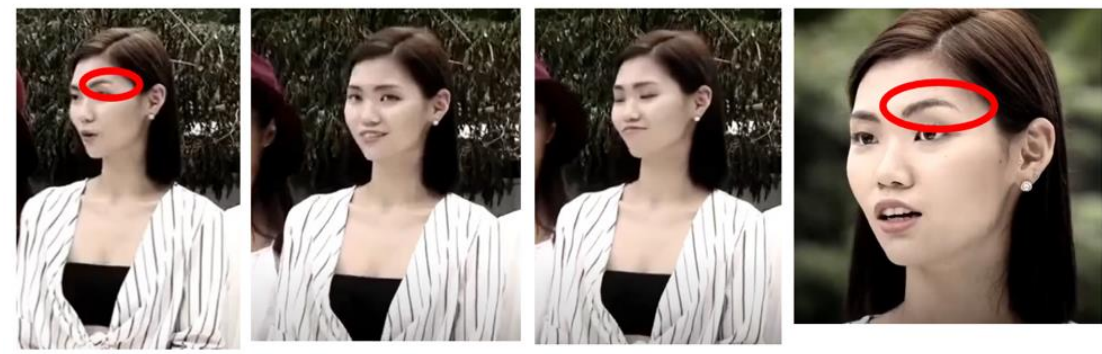

$6 \quad$ SA : $\triangle$ Smiles and raise one of her eyebrows while $G Z$ at $G$ and tingles her head slightly

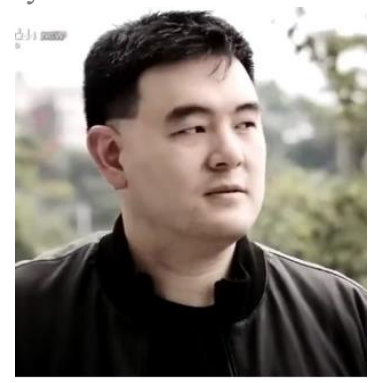

$7 \quad$ G: $\Delta$ shake his head with a dissapointed expression

8 Flashback ends

$9 \quad$ G: ${ }^{\uparrow}$ Who the $\mathbf{F}^{* * *}$ are you to ${ }^{\uparrow}$ roll your ${ }^{\uparrow}$ eyes at ${ }^{\uparrow}$ me!? 
11 G: And, if I'm the client, I would never ${ }^{\uparrow}$ ever gonna ${ }^{\uparrow}$ hire ${ }^{\uparrow}$ you!

12 (7.0)

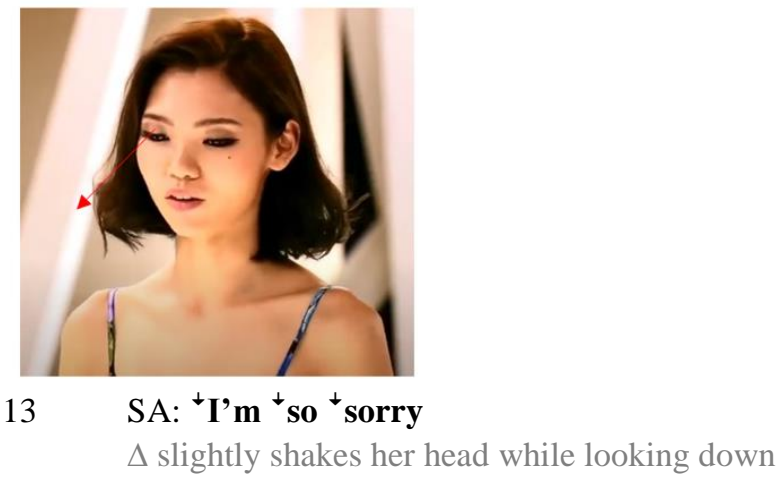

14 MJ1: You need a major major attitude readjustment. At the end of the day, girls, you can be the best model on the face of this earth without a client, you don't have a job.

15 SA: $\Delta$ Nods

$16 \quad$ (.)

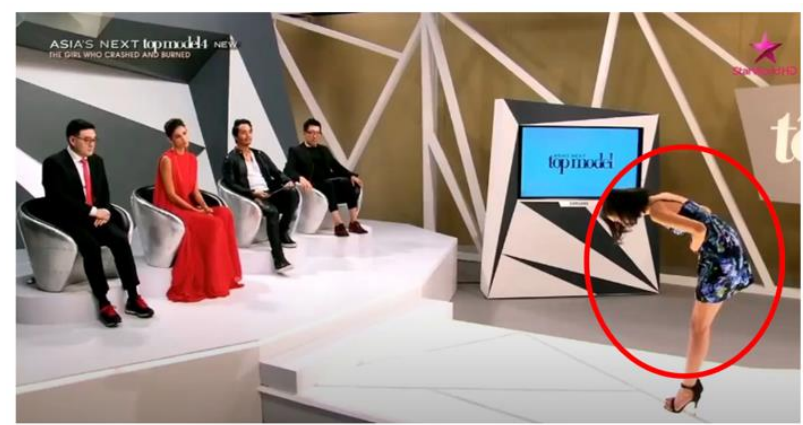

17 SA: Thank you for let me know, I want to apologize in Korean way.

$\triangle$ Bows

$18 \quad($.

19 SA: I'm sorry.

20 MJ2: ${ }^{\circ}$ That wasn't easy for her, I'm sure. ${ }^{\circ}$

Our first data was the video where a Korean native speaker met a native English speaker talking about their activities yesterday. The first time we recognize was the native Korean speaker speaking with a native English speaker, and there are also audiences in this show. The Korean native speaker apparently does not master English well, and he was having a little bit of a problem while answering some questions from the English native speaker. When the native English speaker asks him what the Korean native speaker did, the Korean native speaker was thinking for a while. As we can see in line 2, there was a time gap of about 3 seconds, and the Korean native speaker started to make some gestures from his hands. In line 3 , the Korean native speaker responded with a loud word 'AH!' indicating that his mind was beginning to work to answer the question. The next thing he did was starting to raise his hands while thinking the correct word to respond to the native English speaker. Based on line 5 in this analysis, the Korean native speaker tried to make a gesture with his arms raised while attempting to answer the questions. According to [3]'s theory about gesturing while talking helps the speaker by facilitating greater flexibility in speaking and even with the recall of words. As the Korean native speaker raises his arms, he finally makes another gesture pointing his head while the native English speaker is gazing at his gesture that we can see in line 5. The English native speaker is constantly staring at him until the line of 19 , giving the meaning of the change of status among the interlocutors. The theory of [3] stated that gazing is one of the intimate gestures that indicate the change of a more intimate status was. As we can see in this study, the English native speaker is trying to closer relationships with the Korean native speaker. This was portrayed as how Emma Stone as Mia in La La Land changed the way she looked at Ryan Gosling's character, and they became more intimate in their relationships [3]. Another body language that successfully transferred its meaning, helping the Korean native speaker speak his mind, was the showering gesture. By looking at the hand gesture that the Korean native speaker 
made, the English native speaker understands that yesterday he was taking his shower and using shampoo to wash his hair.

The second data was a clip of Asia Next Top Model Cycle 4 where a single unconscious body language we made could lead us to a negative reaction from people around us. In line 5, the video gave us a short flashback of the previous episode. When giving a brief to the models, Glenn smiles, but then in line 6 , one of the models named Sang In raised her eyebrow and gently shaking her head. According to [3], the body language of eyebrow asymmetry holds the meaning of uncertainty and doubt. The model might do not realize what she had made in her body language. Still, this certain gesture undoubtedly indicates that the model was uncertain about something related to the photoshoots. As the Navarro theory stated, the asymmetry of an eyebrow means that the person is questioning and doubting what the speaker said. Unfortunately, this causes a significant negative reaction for Glenn (one of the judges). This means that the body language given from Sang In to Glenn succeeded since Glenn understood what Sang In might want to say. Another body language that Sang In did was bowing in line 17. While she was bowing, she apologies with a vibrating voice. As she mentioned in the data of this study, bowing is a formal Korean way of apologizing. This body language was accepted by the judges and indicating that the body language succeeded in holding the role as a bridge between interlocutors as how the result of the study that has been conducted by [5] stated that the two-person who use body gestures are able to continue their communication even though they were having trouble while talking since they did not have mastered English as a lingua franca.

\section{CONCLUSION}

This study was meant to analyze how body language can be a lingua franca for multilingual interlocutors, as humans communicate with our vocal organs and our body. The result indicates that body language can be a lingua franca since two different native speakers can still communicate with each other even though one of them is having a hard time searching for the right word to interpret and portray his mind. The point of communication is both of the interlocutors are understand each other. This happens with a similar case where the second data, the Korean model, and a client have a rough past while taking some photoshoots, as mentioned in the data used in this study. The client was not very happy with the 'attitude' of the model since it was insulting him. Still, then the Korean model immediately apologized in a Korean way by bowing to the client and the judges. The judges and the client accepted the formal and polite body language she used. This study had used the methods of multimodal transcript and qualitative method to complete the analysis. Some errors possibly persist that might be a good point for further research in the field of Lingua Franca and Body Language into a different and broader insight.

\section{REFERENCES}

[1] D. Abercrombie, "Paralanguage," British Journal of Disorders of Communication, vol. 3, no. 1 , pp. 55-59, 1968. DOI: https://psycnet.apa.org/doi/10.3109/1368282680 9011441

[2] R.J. Hoffmeister and J.P. Gee, "American sign language," Discourse Processes, vol. 6, no. 3. 1983.

DOI: https://doi.org/10.1080/01638538309544563

[3] J. Navarro, Dictionary Body Language: A Field Guide to Human Behavior. UK: Harper Collins, 2018.

[4] J. Holmes, An Introduction to Sociolinguistics. $4^{\text {th }}$ ed. NY: Routledge, 2013.

[5] Y. Matsumoto and S. Canagarajah, "The use of gesture, gesture hold, and gaze in trouble-in-talk among multilingual interlocutors in an English as a lingua franca context," Journal of Pragmatics, vol. 169, pp. 245-267, 2020. DOI: 10.1016/j.pragma.2020.08.015

[6] I. Wirasari and R. Indah, "The Study of The Meaning of Body Language and Perceptions of Audience Garuda Indonesia Television Commercials Hands Version," in Proc. of the $3^{\text {rd }}$ International Conf. on Creative Media, Design, and Technology (REKA 2018), vol. 207, no. Reka, pp. 62-65, 2019. DOI: 10.2991/reka18.2018.14

[7] L. Litosseliti, Research Methods in Linguistics. London: Continuum, 2010.

[8] R. Wardhaugh, An Introduction to Sociolinguistics. Oxford: Blackwell Pub., 2006.

[9] S.C. Levinson, Pragmatics. Cambridge, University Press, 2005.

[10] H.P. Grice, "Logic and Conversation," in Syntax and Semantics 3: Speech Arts, Cole et al., 1975, pp. 41-58.

[11] A. Wray, K. Trott, A. Bloomer, S. Reay, and C. Butler, Projects in linguistics a practical guide to researching language. Hodder Education Pub., 1998. 
[12] C. Hadiati, "The Speech Acts and Conversational Implicature of Wise's The Sound of Music," LEKSIKA, vol. 3, no. 3, pp. 1-16, $2009 . \quad$ Available: http://jurnalnasional.ump.ac.id/index.php/LEKS IKA/article/view/2258

[13] L. Mondada, "Challenges of multimodality: Language and the body in social interaction," $J$. Socioling., vol. 20, no. 3, pp. 336-366, 2016.
DOI: 10.1111/josl.1_12177

[14] University Transcription Services, "Jefferson Transcription System." [Online]. Available: https://www.universitytranscriptions.co.uk/jeffe rson-transcription-system-a-guide-to-thesymbols/ [Accessed May 21, 2021].

[15] L. Mondada, "Conventions for multimodal transcription," Lorenza Mondada, pp. 1-8, 2019. 